\title{
EL FRUSTRADO PROYECTO PARA PANTEÓN Y SEPULCRO DEL DUQUE DE SESSA EN BAENA
}

\author{
Francisco Manuel Carmona Carmona ${ }^{1}$ \\ Universidad de Córdoba
}

\begin{abstract}
En el presente trabajo damos a conocer las trazas inéditas de panteón y sepulcro realizadas por el arquitecto real Juan Gómez de Mora (1586-1648) a iniciativa del duque de Sessa y Baena, don Luis Fernández de Córdoba y Folch de Cardona (1582-1642), quien se plantea acometer la readaptación de la antigua cripta familiar y la realización de un sepulcro particular en la capilla principal de Santa María la Mayor de Baena a partir de las informaciones de Luis González Bailén (1580-1655). Contextualizamos la relación de los tres personajes a partir de estos proyectos monumentales, a la vez que asistimos a un cambio en la estrategia del duque por medio de la cual antepone a la necesidad personal de sepultura el dar prioridad en proveer de un digno enterramiento a su linaje, lo que llevaría implícito su prestigio personal.

Palabras clave: Luis Fernández de Córdoba y Folch de Cardona, duque de Sessa y Baena; Juan Gómez de Mora; Luis González Bailén, cantero; iglesia Santa María la Mayor de Baena; siglo XVII; trazas; enterramiento.
\end{abstract}

\section{THE FRUSTRATED PROJECT FOR A VAULT AND SEPULCHER OF THE DUKE OF SESSA IN BAENA}

In this article the author presents the heretofore-unknown traces of the vault and sepulcher carried out by the royal architect Juan Gómez de Mora (1586-1648) at the initiative of the duke of Sessa and Baena, Don Luis Fernández de Córdoba y Folch de Cardona (1582-1642). Based on information provided by Luis González Bailén (1580-1655), the Duke considered undertaking the adaptation of the old family crypt and the creation of a private sepulcher in the main chapel of Santa María la Mayor of Baena. The relationship among these three men is contextualised through these monumental plans. They also provide an understanding of the change in the Duke's strategy: he prioritized providing a respectable burial place for his lineage over that of his own burial requirements, thereby implicitly augmenting his personal prestige.

Key words: Luis Fernández de Córdoba y Folch de Cardona, duke of Sessa \& Baena; Juan Gómez de Mora; Luis González Bailén, stonemason; church of Santa María la Mayor of Baena; 17th century; traces; burial.

Como citar este artículo/Citation: Carmona Carmona, Francisco Manuel (2017): "El frustrado proyecto para panteón y sepulcro del duque de Sessa en Baena”. En: Archivo Español de Arte, vol. 90, núm. 357, Madrid, pp. 19-30; doi: 10.3989/aearte.2017.02.

Desde el siglo XIII una costumbre muy extendida entre la élite social europea fue establecer como lugar más adecuado de enterramiento las iglesias, catedrales y conventos como fundamental instrumento para perpetuar en los vivos la imagen del poderoso difunto durante los oficios. A ello contribuía un meditado programa iconográfico, la heráldica, los epitafios e incluso la efigie como medio legitimador del estatus de la familia, a la vez que actuaban como último intento de eludir el olvido de los allí sepultados. Así, esta práctica funeraria fue evolucionando a

\footnotetext{
1 aa2carcf@uco.es / ORCID iD: http://orcid.org/0000-0003-1118-3271
} 
lo largo de los tiempos, hablando de una intención de perpetua propaganda tanto en la destreza y originalidad del artista como en la intención de dejar entrever en el efigiado la expresión de nobleza y pureza de una estirpe.

De este modo lo entendieron los miembros de una de las ramas de los Fernández de Córdoba, los condes de Cabra, quienes contaron desde antiguo en la capital cordobesa con una capilla en la Real Colegiata de San Hipólito y, más tarde, con la capilla mayor del monasterio de monjas jerónimas de Santa Marta como lugar de póstumo descanso de su linaje. Pero a comienzos del siglo XVI, surgió un proceso por el cual la nobleza traslada sus enterramientos familiares desde Córdoba a las capitales de sus señoríos'; por lo que, quien fuera quinto señor de Baena y tercer conde de Cabra, cambia el emplazamiento fúnebre familiar a la capilla mayor de la iglesia de Santa María la Mayor de Baena ${ }^{3}$. Si bien es cierto que llama la atención la escasa utilización de un espacio tan principal como lugar de descanso de los miembros fallecidos de este linaje.

Desde comienzos del segundo tercio del siglo XVI se prefiere para este fin otro sagrado emplazamiento, la iglesia del lindero convento de Madre de Dios ${ }^{4}$, que fuera también fundación del tercer conde de Cabra. Serán sus descendientes, los quintos duques de Sessa, quienes comiencen a considerar la capilla mayor de la iglesia del convento Madre de Dios de Baena como su panteón ${ }^{5}$, contribuyendo con ello a establecer en este cenobio un espacio donde perpetuar la identidad, el poder y el patrocinio, y mediante el cual enraízan las familias señoriales con sus dominios a través de sus muertos y antepasados. Por esto don Antonio "pidió la capilla y entierro de esta casa para que lo fuese propia y perpetua para sí con intento de adornarla, autorizarla y engrandecerla como lo comenzó a hacer desde Roma enviando el edificio y retablo que está puesto de piedra en el altar"6.

\section{El duque de Sessa y la estela del panteón real de EI Escorial}

Conocemos la animadversión de la nobleza española a alejarse de la corte, de las ceremonias palatinas y los múltiples acontecimientos notables de la vida madrileña. Don Luis Fernández de Córdoba y Folch de Cardona, vi duque de Sessa y IV duque de Baena, será de ello un claro ejemplo, pese a que la opinión que en Madrid se tenía de él no era del todo halagüeña, por estar considerado como "persona que no inspiraba o merecía confianzas políticas o discusiones intelectuales", de ahí que se viera menospreciado al intentar conseguir cualquier cargo áulico ${ }^{7}$.

Pero lejos de desfallecer en su ánimo por alcanzarlo, la abundante correspondencia mantenida con su secretario personal -el poeta Lope de Vega- nos muestra a un noble en constante ejercicio de sobreponerse a los innumerables reveses personales por no recibir cargos de influencia. Prueba de ello es que a comienzos del mes de septiembre de 1627 el duque se encuentra en

\footnotetext{
2 Urquízar, 2000: 786.

3 Fernández de Córdoba, Abad de Rute, 1962: 377-379. Los estatutos de fundación de esta capilla datan de 1497 y se encuentran transcritos en Archivo Histórico de la Nobleza (AHNOB), Fondo Baena, Caja (C.) 208, Documento (D.) 149 .

${ }^{4}$ Especialmente elocuente es el Libro de los entierros q[ue] ay en el coro y en la yglesia de los señores desta Casa, donde hasta $c a .1645$ se enumeran y relatan las implicaciones que para con el convento de Madre de Dios de Baena tuvieron los múltiples bienhechores y miembros de la casa de Cabra allí enterrados. Archivo Conventual Madre de Dios de Baena (ACMDB), C.4. ca.1645.

5 Fernández de Béthencourt llega a denominar al convento de Madre de Dios de Baena como 'panteón' de la Casa de Cabra en múltiples ocasiones; a veces equivocando el verdadero destino de los restos de distintos personajes que, según delata la documentación utilizada, irían a tomar sepultura a la cripta de la vecina iglesia de Santa María la Mayor. 2003: passim tomo (t) 6 y 7 .

${ }^{6}$ ACMDB, C.1, Libro de la Hacienda que este Convento de Madre de Dios tiene y de los papeles de más consideración que en su archivo están..., f. 271r. E incluso doña Juana "después de viuda prosiguió la obra iniciada por su marido de enriquecer la capilla mayor de la Madre de Dios de Baena, noble enterramiento de su Casa" Fernández de Béthencourt, 2003: t.7, 113.

7 Aspectos diversos del duque de Sessa en González de Amezúa, 1989: t. I; Ferrer, 2008 y Wright, 2007.
} 
Baena $^{8}$, donde lleva a cabo una serie de actuaciones destinadas a reafirmar su poder señorial, eligiendo la iglesia de Santa María la Mayor como locus ideal desde donde representar su autoridad. De este modo, dispone que en ella se realice la necesaria renovación del aparato ritual de los oficios religiosos ${ }^{9}$ y establece un modelo reglado de jerarquía entre las élites locales y su señorío a través de la ceremonia ${ }^{10}$. Además de esto, y lo que es para nuestro cometido más importante, impulsa una importante readaptación arquitectónica de la capilla mayor parroquial como visual expresión de la grandeza de su familia a través de la erección de un monumento funerario para sí, sus antepasados y descendientes ${ }^{11}$.

Con esta iniciativa Sessa se une a lo que gran parte de la alta nobleza española viene realizando desde comienzos del siglo XVII al intentar emular lejanamente con la construcción de capillas y panteones lo que supuso la construcción del Panteón Real de El Escorial ${ }^{12}$. Allí se conjugaron en hábil sintonía el aspecto simbólico con la suntuosidad de los materiales preciosos, la escultura y el cromatismo, convirtiéndose en paradigma de monumento funerario que se presta a imitar por la aristocracia y nobleza española. Así debió de entenderlo el duque de Sessa, pues acude al arquitecto Juan Gómez de Mora para llevar a cabo su obra de rehabilitación de la capilla mayor baenense, quien por su condición de responsable de las obras reales participó en la remodelación y transformación definitiva del lacunario real ideada por Juan Bautista Crescenzi ${ }^{13}$.

Pese haber participado en el panteón escurialense su repercusión no fue tanta, pues Juan Gómez de Mora no se prodigó en este tipo de obras de carácter funerario, aunque en las que realizó "aplicó un criterio personal de carácter estructural antes que ornamental, mostrándonos una experiencia de suma sencillez como corresponde en enterramientos no demasiado amplios" 14 . Entendemos por tanto, que dando a conocer las trazas realizadas para el panteón del linaje y sepulcro del duque de Sessa en la parroquial baenense, contribuimos a incrementar el catálogo de este artista.

\section{Gómez de Mora y la monumentalización del panteón ducal baenense}

La documentación manejada en el Archivo Histórico de la Nobleza nos informa que a finales de 1626 ya había una intención de acometer algún tipo de reforma en la cripta de la capilla mayor de Santa María la Mayor de Baena, puesto que su capellán mayor envía al duque una planimetría del alzado del altar mayor y de la planta de la bóveda de la capilla ${ }^{15}$ (fig. 1). La misma nos informa sobre el lugar por donde se accede a la cripta, el lateral derecho de la mesa de altar, del que parte una escalera hasta el espacio abovedado destinado a enterramiento.

A comienzos del año 1628, coincidiendo con una estancia del duque en Baena, se documentan una serie de iniciativas que señalan la necesidad de reorganizar la bóveda a fin de facilitar el acceso y aumentar su capacidad. Es evidente la implicación del duque en la reforma del panteón familiar ordenando que se renueven los ataúdes donde reposan sus antepasados y mostrando su intención de ser sepultado bajo el altar mayor de Santa María, a partir del cambio de ubicación

\footnotetext{
8 González de Amezúa, 1989: 137-145.

9 AHNOB. Baena, Carpeta (CP.) 322, D.28.

${ }_{10}$ AHNOB. Baena, C.32, D.9.

11 AHNOB. Baena, C.23, D.7-12 y CP.462, D.20-23 y 30.

12 Sobre el origen, vicisitudes y artífices del Panteón Real del Monasterio del Escorial es lectura obligada Bustamante, 1992.

13 Desde antiguo se viene atribuyendo el Panteón Real como obra de Juan Gómez de Mora. Nuevas lecturas del monumento y el rastreo documental han propiciado señalar a Juan Bautista Crescenzi como su responsable último y superintendente del edificio, pese a su desconocimiento de los aspectos técnicos o de cantería, los cuales recaían en el Arquitecto de Su Magestad Juan Gómez de Mora. Bustamante, 1992: 176 y Blanco, 2002: 236-246.

14 Tovar, 1986: 83.

15 AHNOB. Baena, CP.462, D.21.
} 


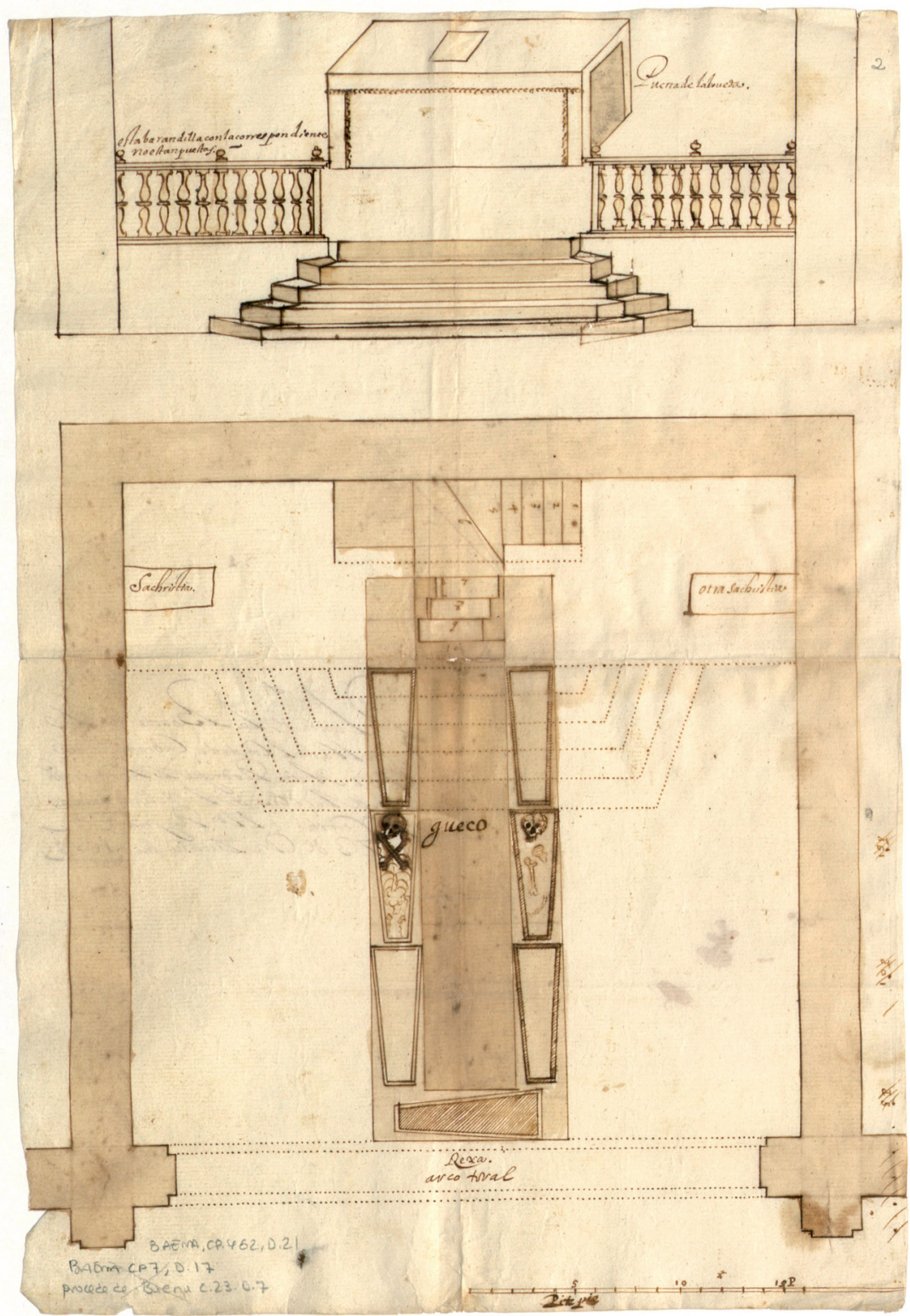

Fig. 1. Antón

Rodríguez Pintado, 23/12/1626. Alzado del presbiterio y planta de la bóveda en la capilla del conde de Cabra de la iglesia Santa María la Mayor de Baena. (AHNOB. Baena, CP.462, D.21).

de la escalera como solución a tan exiguo espacio ${ }^{16}$. Pero en el verano de ese mismo año don Luis regresa a la corte y el proyecto de reforma de la cripta sepulcral queda a la espera de nuevas motivaciones ${ }^{17}$.

De nuevo en 1634 nos encontramos al duque en sus estados cordobeses, por lo que la idea de culminar la obra emprendida seis años atrás toma fuerza. Principalmente porque en 1630 falleció su esposa, doña Mariana de Rojas, motivo por el que pidió información sobre el estado del pan-

\footnotetext{
${ }^{16}$ AHNOB. Baena, C.124, D.65; C.23, D.9 y D.8.
}

17 González de Amezúa, 1989: t.i, 145-148. 
teón familiar a su maestro de obras, Luis González Bailén ${ }^{18}$, quien remite su informe ${ }^{19}$ en diciembre de 1633 desde Cabra junto a la planta de la capilla ${ }^{20}$. Sessa la envía al arquitecto real Juan Gómez de Mora para que realice un proyecto de adecuación del espacio mortuorio y diseñe los sepulcros ducales que debieran ocupar la capilla mayor parroquial. Es a partir de entonces cuando asistimos a un cambio significativo en la concepción de este encargo ducal, que pasa desde una personalísima necesidad de enterramiento a una pretendida materialización arquitectónica en favor de la visibilidad del poder y el esplendor del linaje, lo que redundaría consiguientemente en el prestigio del comitente.

Pese a que únicamente el cometido del encargo ducal suponía informar sobre las dimensiones de la capilla de Santa María la Mayor, el maestro de obras del duque no dudó en incluir dos diseños de sepulcro, uno junto al dibujo de la planta para demostrar la anchura del muro y, por si éste no fuese del gusto de Sessa, otro "borrador que yo tenía hecho para un entierro del duque de Béjar que me pidieron, cualquiera de ellos que se haga será muy bueno, y habiéndolo de corregir y hacer nueva traza el maestro mayor de su majestad [pues su intención era que la tuviese en cuenta Gómez de Mora, como así fue] vendrá con mayor primor y ventajas"21.

El proyecto de reforma de la cripta de Gómez de $\operatorname{Mora}^{22}$ (fig. 2) plantea la posibilidad de que la bóveda sea ampliada a todo el área bajo la capilla mayor, con lo que se triplicaría el espacio destinado a enterramiento mediante el vaciado del maciço a ambos lados de la bóveda existente, tomando todo el sitio de la capilla mayor hasta sus cimientos, lo que supondría conseguir un habitáculo próximo a los $78 \mathrm{~m}^{2}$, y profundizar a nivel del suelo hasta conseguir cerca de $4 \mathrm{~m}$. de altura $^{23}$.

Se conseguiría con esta propuesta una cavidad diáfana que precisaría realizar "nuevos cimientos para hacer los nichos, bóvedas y capillas que se demuestran en la traza" 24 . La obra requeriría acometerla por fases, comenzando por forrar interiormente el cimiento viejo con un nuevo y potente muro, que serviría a su vez para instalar los nichos.

18 A Luis González Bailén nos lo presenta la historiografía como reputado cantero y figura clave en el triunfo y difusión del uso de mármoles y jaspes como material por excelencia en construcciones a gran escala. Debió conocer los rudimentos de la cantería a través de su padre, quien desde comienzos del siglo XVII ejecutaba importantes encargos en su Priego natal y, hacia 1613, lo encontramos establecido a pie de cantera en la cercana Cabra, donde entra en contacto con el cantero local Juan de Morales, con quien colabora en distintos encargos en Écija y Marchena en un momento en el que la Compañía de Jesús estaba ultimando la construcción y decoración de sus colegios e iglesias en estas localidades sevillanas. Seguramente por haberlo conocido trabajando en Écija, a partir de 1618 participa junto al jesuita Alonso Matías en el retablo mayor de la catedral de Córdoba, para más tarde encontrarlo obligado de "labrar y acabar y sentar todo el xaspe que fuere necesario" en el trascoro de la catedral de Sevilla. Estos y otros datos sobre la figura y obra de Luis González Bailén en Galera, 1982: 99 y 127; Peláez, 1985; Moreno, 1986; Rivas, 1990: 34-49; Nieto, 1998: 540-541.

19 AHNOB. Baena, C.23, D.10.

20 AHNOB. Baena, CP.462, D.24.

21 AHNOB. Baena, C.23, D.10, f.1. La traza del sepulcro solicitado por el duque de Béjar en AHNOB. Baena, CP.462, D.25.

22 AHNOB. Baena, C.23, D.11. "En M[adri] a 19 de abril de 1636/Juan Gomez de Mora aposentador mayor de su Mgd/Da su pareçer s $\mathrm{s}^{\mathrm{e}}$ la planta de la capilla mayor de la $\mathrm{v}^{\mathrm{a}}$ de Vaena y entierro $\mathrm{q}^{\mathrm{e}}$ se pretende hazer con el arco y urnas a cada uno de los dos lados de la epistola y evangelio". Esta documentación estaría enriquecida con dos diseños actualmente segregados de ella. En uno se trazan dos plantas: la de la capilla mayor, que ocupa la mitad superior, y la del panteón propuesto en su mitad inferior: AHNOB. Baena, CP.462, D.23. El otro diseño es una sección de la capilla mayor donde traza el arquitecto real en el muro del evangelio su propuesta de monumento funerario: AHNOB. Baena, CP.462, D.22.

${ }^{23}$ Se ha realizado el cálculo atendiendo al pitipié en tercias de vara del propio plano, usando el valor de la tercia a $27,863 \mathrm{~cm}$.

${ }^{24}$ AHNOB. Baena, CP.462, D.23 [mitad superior] "Planta de la capilla mayor de la Villa de baena donde se demuestra el sitio en que se an de poner los nichos de los entierros a los lados de la epistola y ebanjelio conforme a la traça de su alçado que para este efeto se a echo que ba con esta entrada i escalera para bajar a la bobeda de abajo [rúbrica]". 


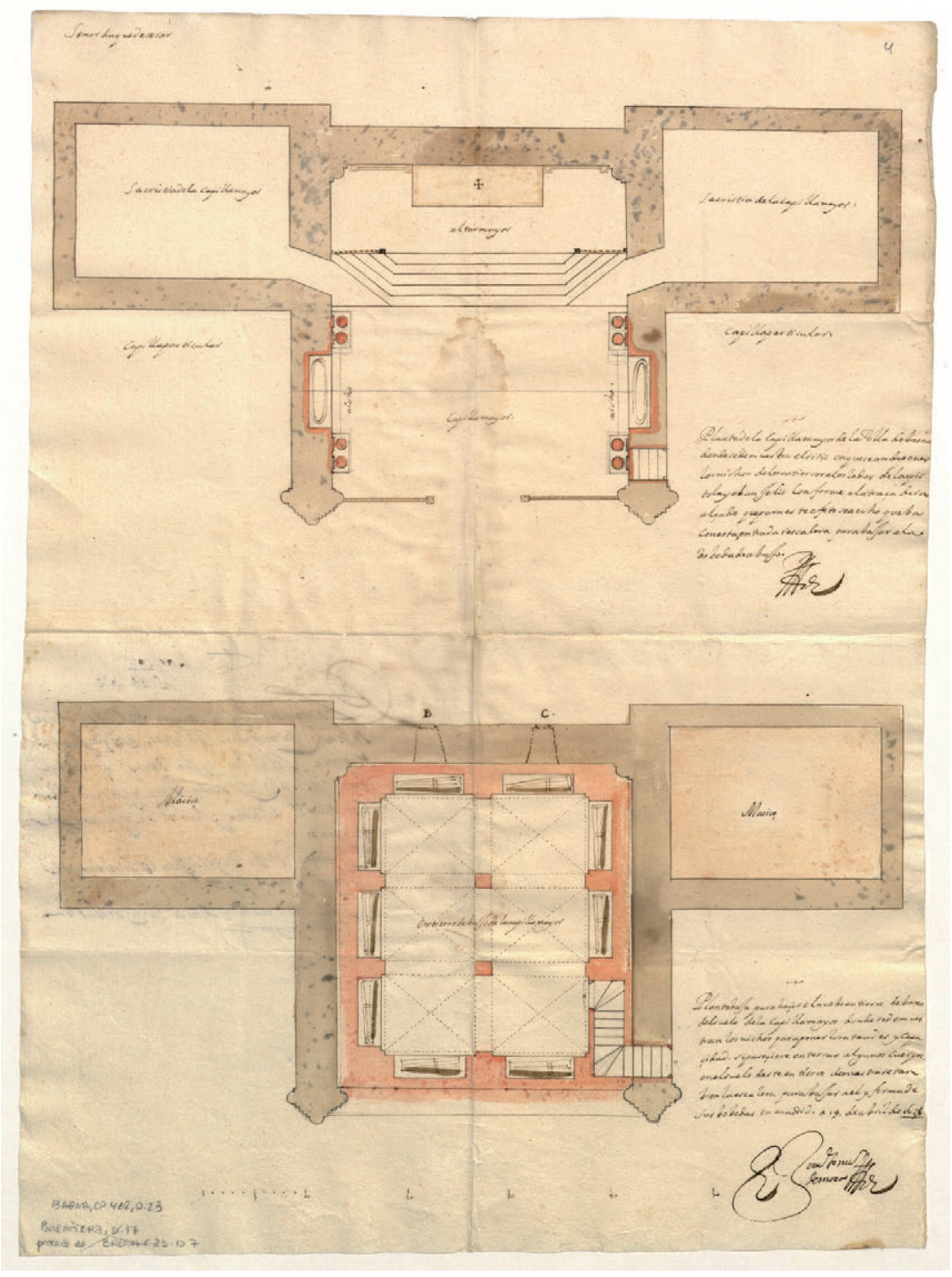

Fig. 2. Juan Gómez de Mora, 19/04/1636. Planta de la capilla mayor con sección de la propuesta de sepulcros en muros del evangelio y epístola; y planta de la propuesta de panteón en subsuelo de la capilla mayor de Santa María la Mayor de Baena. (AHNOB. Baena, CP.462, D.23).

Sobre el plano se traza una planta con dos naves y tres tramos, separados por dos pilares intermedios que enlazan por arcos de medio punto con pilastras adosadas al muro, dando lugar a diez arcosolios. Se cubriría el espacio con seis bóvedas de arista. Continúa el aposentador real dando su solución al número y disposición de lóculos y lucillos, pues de este modo "se pueden hacer nueve nichos y en cada uno de ellos se pueden poner tres ataúdes" 25 .

Respecto al acceso al panteón da el visto bueno a la solución aportada por González Bailén de acceder por la capilla colateral26, dado que la vara y cuarta de grosor del muro permitiría

25 AHNOB. Baena, C.23, D.11.

${ }^{26}$ Donde además aporta una genial solución al problema del acceso a la bóveda sepulcral: "Si Vx. ${ }^{\text {a }}$ quisiere darle escalera a la bobeda que oy sirbe en la capilla se le puede dar por la capilla colateral ques de particular y oy esta hecha una puerta que pasa el grueso de la pared a donde esta sinificada una escalera en la planta y ay una +". Se trataría de horadar el muro del evangelio de la contigua capilla de San Gregorio, con lo que se ganaría distancia en el tramo de escalera y así verse favorecida la visual de sendos ataúdes bajo el altar de la capilla mayor. AHNOB. Baena, C.23, D.10 
bajar a él cómodamente a través de un tramo de escalera en doble recodo, pero sacrificando el espacio del décimo arcosolio.

Le preocupa a Gómez de Mora la cuestión de la iluminación y ventilación del interior de la cripta, algo que inquietó desde un primer momento también en El Escorial, por lo que para solventar el problema se propone una solución idéntica ${ }^{27}$ al abrir sendos vanos en el muro oriental sobre la parte alta de los dos lóculos situados bajo el altar mayor, aunque se pierdan dos lugares para ataúdes.

El dominio teórico y compositivo de Gómez de Mora en el desarrollo de nuevos espacios, ambientes y elementos arquitectónicos le obligan a plantear una fundamental condicionante para la ejecución de su proyecto en Baena, "por no saber qué género de fábrica es la que allí más se acostumbra no doy mi parecer en esto"; por lo que una vez vista y reconocida la planimetría del maestro de obra, pide a éste le haga saber "las dificultades que se ofrecen y de qué género de materiales se pueden ejecutar" 28 .

En la práctica, la propuesta de Gómez de Mora para panteón ducal supondría ampliar considerablemente el espacio y número de enterramientos, pasando de los seis u ocho existentes a los veintisiete lóculos propuestos por el arquitecto real y, como ocurriera en el panteón real, agrupar en una misma cámara los cadáveres de su estirpe en sarcófagos similares que simbolizaran la igualdad ante la muerte.

\section{Un sepulcro de mejor adorno y mas fundada arquitectura}

En la traza de González Bailén (fig. 3) donde se incluye una propuesta de sepulcro con estructuras y elementos de evidente inspiración en tratados italianos y destacando la urna funeraria rematada por una herreriana pirámide sobre bolas, que -siendo una de las formas arquitectónica más perfecta del clasicismo- alude simbólicamente al mausoleo y a la eternidad. Asimismo debemos señalar de este diseño el escaso criterio diferenciador en las dimensiones entre cuerpo y ático, tal vez por la tendencia del maestro de obras a realizar portadas arquitectónicas. Todo lo contrario de lo que ocurre en su propuesta para el sepulcro del duque de Béjar, donde modula mejor las distintas partes y elementos siguiendo criterios vignolescos ${ }^{29}$.

Por su parte, Gómez de Mora completa su informe refiriéndose al diseño de sepulcro propuesto por González Bailén sin atender al borrador de traza para el supuesto entierro del duque de Béjar. Lamenta que los entierros no se puedan disponer centrados en las paredes laterales de la capilla por la presencia de la tribuna del altar mayor y las puertas de acceso a las sacristías. No cabe duda de que el Maestro de las Obras Reales lo que pretende es enfatizar el carácter funerario del templo enfrentando sendos sepulcros, a modo de reinterpretación de los cenotafios broncíneos de la basílica escurialense.

Respecto al diseño de sepulcro de González Bailén advierte el arquitecto real que su pedestal resulta muy bajo y queda con poca decencia, tanto para colocar el lucillo como para poner las correspondientes cartelas. Lo tilda de pobre en su ornato y echa en falta la presencia de columnas en el mismo. Pone el acento en el ático, donde se disponen las armas del linaje, considerándolo desproporcionado respecto al cuerpo.

Así las cosas, no duda en recomponer la propuesta del cordobés "para que esta obra quede de mejor adorno y más fundada arquitectura" ${ }^{30}$ y envía un proyecto de monumento funerario ${ }^{31}$ (fig. 4)

${ }^{27}$ El encargado de dotar al panteón real de luz y ventilación fue Alonso Carbonel en torno a 1638, con una propuesta similar a la que Gómez de Mora propuso dos años antes como solución en Baena. Martín González, 1959: 211 y Bustamante, 1992: 194.

28 AHNOB. Baena, C.23, D.11.

29 Evidente es la utilización en determinadas estructuras y elementos de la Regla de Vignola.

30 AHNOB. Baena, C.23, D. 11.

31 AHNOB. Baena, CP.462, D.23 [mitad inferior] "Planta baja para haçer el nuebo entierro debaxo del suelo de la capilla mayor donde se demuestran los nichos para poner los ataudes y capaçidad si pareçiere enterrar algunos cuerpos 

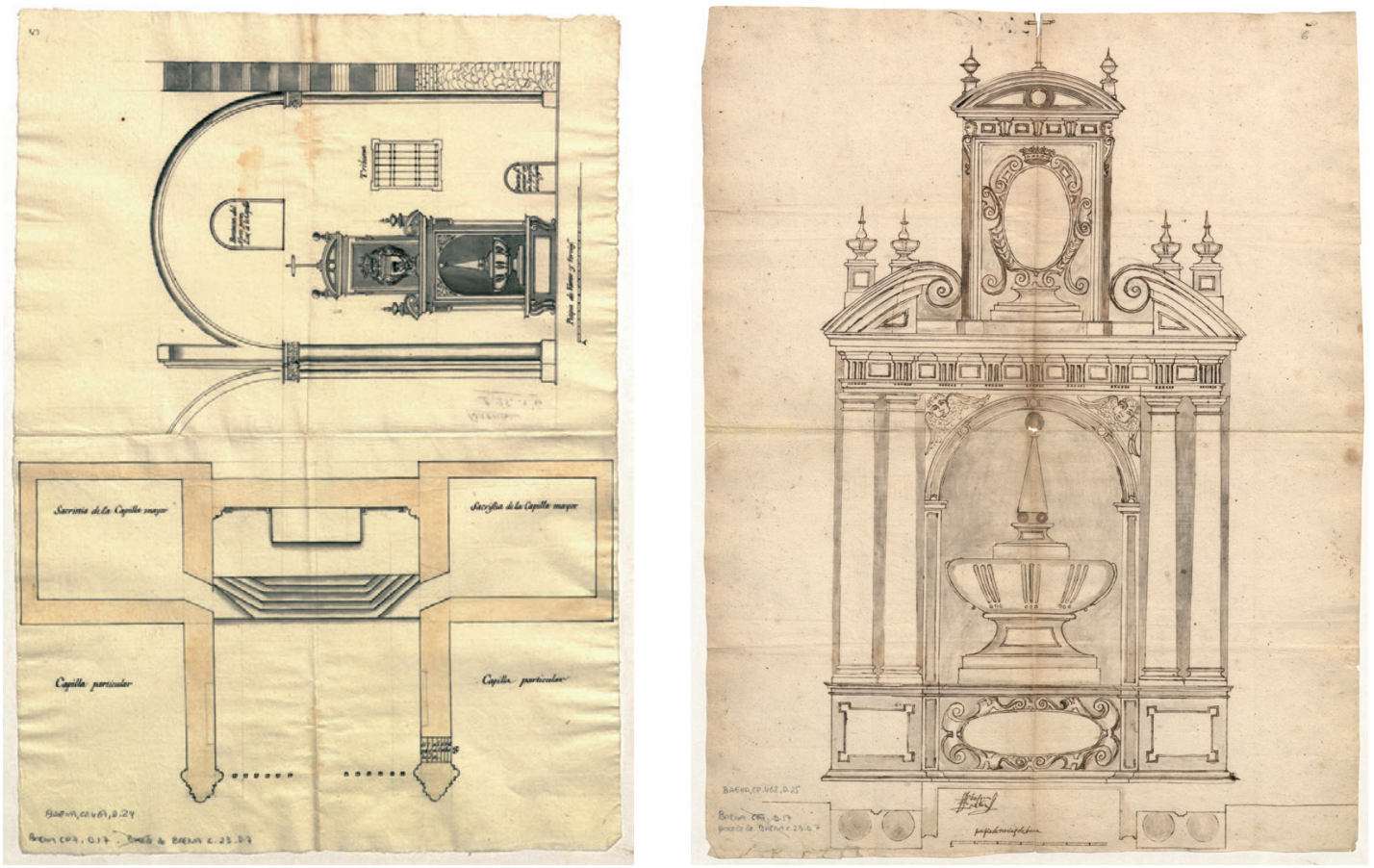

Fig. 3. Luis González Bailén. Propuestas de sepulcro del duque de Sessa en la capilla mayor de Santa María la Mayor de Baena. Izquierda: 14/12/1633 (AHNOB. Baena, CP.462, D.24). Derecha: ca.1630, previamente ofrecida al duque de Béjar (AHNOB. Baena, CP.462, D.25).

que muestra innegables similitudes con la propuesta ofrecida por González Bailén al duque de Béjar.

Resulta difícil justificar cómo, mostrando tanto ingenio González Bailén en el monumento funerario propuesto a Béjar, presenta a Sessa otra traza tan inferior en suntuosidad. Quizá la respuesta resida en que propuso al duque un proyecto original en el que toma protagonismo la heráldica, aunque tampoco debemos despreciar la idea de que deseara presentar diferentes opciones ajustadas a distintos presupuestos y, por consiguiente, fuera una estrategia para asegurarse el encargo ${ }^{32}$. Por su lado, en Gómez de Mora encontramos un proyecto con mayor definición estructural y donde la proporcionalidad del ático con el resto de elementos delata una mejor utilización del lenguaje arquitectónico de la obra en su entorno, y por tanto alejado del servilismo que demuestra el maestro de obras local.

Hubieron de pasar más de tres años para que Juan Gómez de Mora tuviera conocimiento del tipo de terreno sobre el que se asienta la capilla mayor, y poder ver las muestras de los materiales propuestos para su proyecto de panteón y sepulcro en Santa María la Mayor. La información

en el suelo deste entierro, demuestrase tanbien la escalera para bajar a el y forma de sus bobedas. en Madrid a 19 de abril de 1636 [firma y rúbrica]"; y AHNOB. Baena, CP.462, D.22 "Traça de la capilla mayor de la Villa de baena y entierro que se pretende haçer con el arco y urnas a cada uno de los lados de la epistola y ebanjelio y asimismo se demuestra la forma que puede tener el entierro que se a propuesto que se puede haçer desde el suelo de la capilla mayor abajo y en casso que pareçiere a proposito el ornato del entierro se puede haçer traça en mayor forma para demostrar las partes de pedestales colunnas cornisas y demas adorno con la proporçion y tamaños que combiene conforme al arte. en Madrid a 19 de abril de 1636 [firma y rúbrica]".

${ }^{32}$ Dada la intención del cantero prieguense de granjearse el oficio de tesorero en los estados de Sessa; como así ocurrió. AHNOB. Baena, C.23, D. 10, f.1v. 


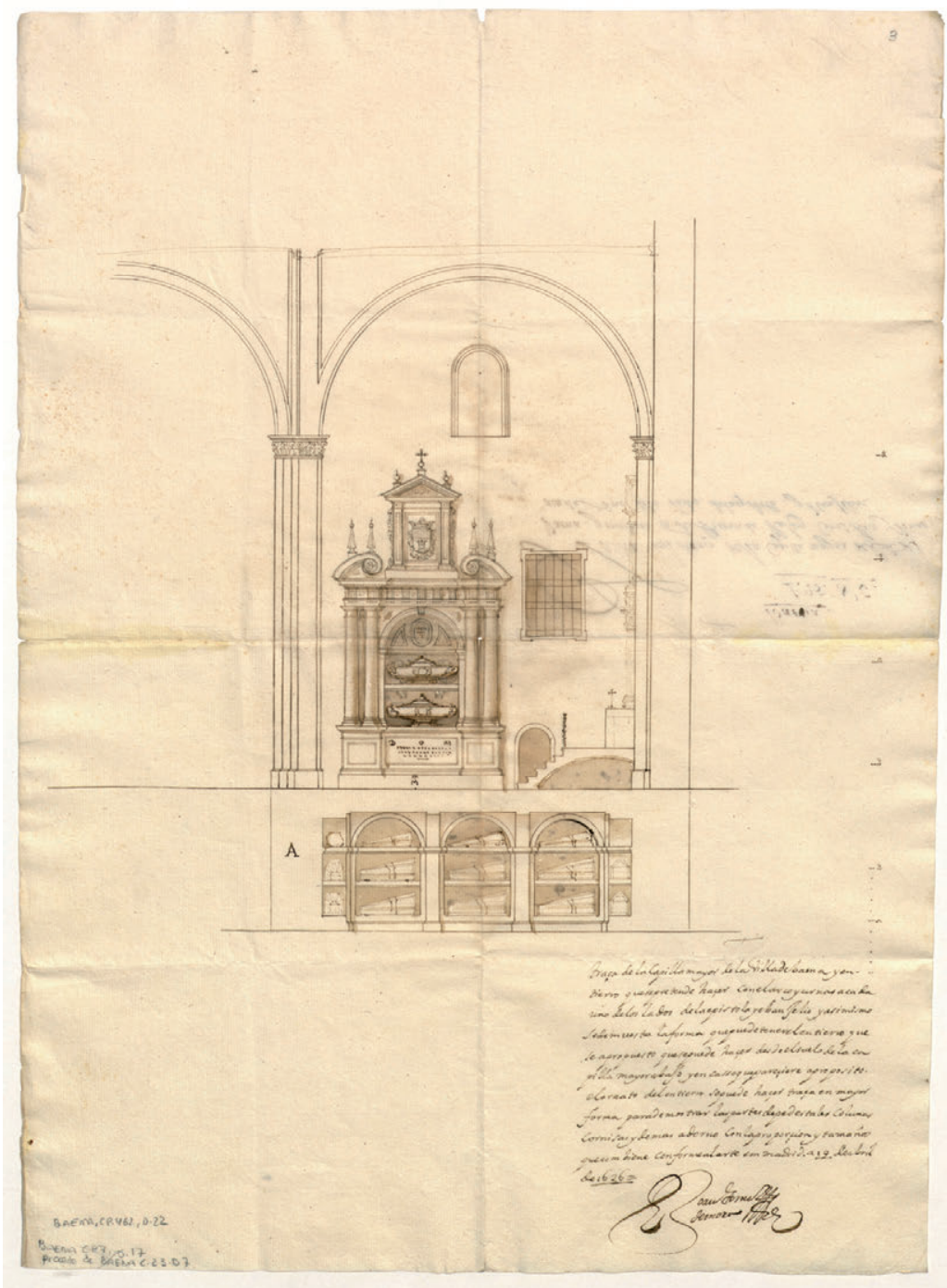

Fig. 4. Juan Gómez de Mora, 19/04/1636. Sección longitudinal de la capilla mayor de Santa María la Mayor de Baena, con indicación de la propuesta de panteón en su subsuelo y diseño de sepulcro en muro del evangelio. (AHNOB. Baena, CP.462, D.22).

le llegó ofrecida en persona, por cuanto hasta la corte madrileña viajó Luis González Bailén, de quien nos advierte en un segundo informe: "mucho me he holgado de ver aquí al Maestro que ha de hacer la bóveda y entierros, pues con su información, se ha salido de las dudas". Se refiere Gómez de Mora a la ya mencionada calidad del terreno, por las dificultades que conlleva la realización de cualquier obra dejando al descubierto los cimientos, y queda tranquilo al saber se trata de "peña viva sobre la que cargan los cimientos, y aunque en ella se corte lo necesario, [...] no puede atormentar la fábrica hecha" 33 .

Entre ambos conciertan tasar la obra en cuatro mil quinientos ducados, en razón a la cercanía de los materiales empleados y ser más barata la mano de obra en Baena que en Madrid, donde podría llegar a valorarse en diez mil ducados, por ser los materiales más caros y los "oficiales hacerse pagar mejor". De igual modo destaca Gómez de Mora la calidad y valor de los materiales mostrados, del mismo modo que da su visto bueno y queda "contento que la persona de Luis

33 AHNOB. Baena, C.23, D.12. 
González Bailén la ejecutará bien, por lo que entendido de su persona y ser Maestro de satisfacción, que importa mucho obras tales se ejecuten con buenas manos" 34 .

Reconocemos a través de estos documentos al Gómez de Mora teórico, matemático y tracista, al hábil enlace entre arquitectura y ornamento, por lo que no deja de advertir que los dibujos enviados son sólo alzados donde prima lo estructural y "se puede hacer traza en mayor forma para demostrar las partes de pedestales, columnas, cornisas y demas adorno con la proporción y tamaños que conviene conforme al arte" ${ }^{35}$. Interesante hubiese sido conocer esta propuesta más minuciosa para el panteón y sepulcro baenense, tanto en los escudos, cartelas, follajes y roleos, así como en el cromatismo que se consigue con los bronces, mármoles y jaspes que sin duda debió pensar utilizar a partir del resultado conseguido por Crescenzi en El Escorial.

Artísticamente, el proyecto de panteón que Gómez de Mora realiza para el duque de Sessa está en la órbita de otros espacios funerarios coetáneos, como el de los duques del Infantado en Guadalajara $^{36}$, y debemos destacar, además, que para Baena el arquitecto real adopta soluciones comunes que se documentan en otras obras suyas; como en la capilla mausoleo de doña Catalina de Medina Zarauz en la madrileña iglesia de San Martín o en la de don Bernardo de Oviedo, del Consejo de Su Majestad y su Secretario ${ }^{37}$. Al igual que en aquellos, encontramos en el proyecto para el duque de Sessa una necesaria y clara referencia a la riqueza y magnificencia en pos de la significación personal, que habría de hacerse visible tanto en la conformación espacial, las estructuras y los materiales, así como en la consiguiente propuesta decorativa que Gómez de Mora realizara para este proyecto de panteón y sepulcro. Además, todo ello nos obliga a conectarlo con quien por expresa recomendación del arquitecto real debía hacerse cargo de ejecutar el mismo, Luis González Bailén, dada su condición de reputado cantero y ser considerado maestro en el uso de estos materiales en Andalucía durante la primera mitad del siglo XVII.

Desgraciadamente este proyecto no llegó a concretarse, ni el panteón bajo la capilla mayor ni los sepulcros situados en sus lados del evangelio y epístola; sin duda, la penuria económica largamente arrastrada por el duque y su muerte en 1642 hicieron decaer tal empresa. Así, su cuerpo fue llevado a enterrar a Baena junto a sus padres y abuelos al convento Madre de Dios, bajo el retablo marmóreo que su padre hizo traer desde Roma. Pero las trazas de Juan Gómez de Mora demuestran que en Santa María la Mayor de Baena se pretendió realizar un magnificente programa de remodelación destinado a exaltar la singularidad del promotor y su linaje.

\section{APÉNDICE DOCUMENTAL}

\section{AHNOB. BAENA, C.23, D.11}

E bisto las traças de la Capilla de la Villa de baena que se an echo por Luis Gonçalez y tiene esta obra dos partes: la una es la bobeda y entierro desde el plano del suelo de la Capilla mayor abajo, y la escalera que se pretende mudar por dentro de una capilla particular. Las otras traças son las que se an echo para haçer dos nichos con sus urnas dentro de la capilla en las paredes correspondientes de epistola y ebanjelio y en estas dos cossas a pareçido lo siguiente:

En la primera obra de la bobeda y entierro que ay devajo de tierra según la traça que Vxa me rremitio se be la estrecheça que tiene este entierro y porque pareçe justo que sea capaz y de mas lustre se a echo una planta de como pareçe se puede haçer mayor tomando para esto todo el sitio de la capilla mayor y sin tocar a los çimientos della se pueden haçer nuebos çimientos para haçer los nichos, bobedas y capillas que se demuestran en la dicha traça, es obra que se a de ir haçiendo a pedaços aRimando con el çimiento biejo cuya forma a de ser como se demuestra en el perfil letra A. Con esto se pueden haçer nuebe nichos y en cada uno dellos se pueden poner tres ataudes, el otro nicho es para la escalera para bajar al dicho

\footnotetext{
${ }^{34}$ AHNOB. Baena, C.23, D.12.

35 AHNOB. Baena, CP.462, D.22.

36 Sanz/Abenza/Garcés, 2007: 847.

37 Tovar, 1986: 82-85.
} 
entierro por la parte y lugar que diçe Luis Gonçalez, a mi entender no allo dificultad ninguna para poner en execuçion esta traça y con ella quedara el entierro muy capaz de buena fabrica y bajar a el con mucha comodidad.

Otrosi seria gran cossa ver si se podria dar alguna luz por las formas de los arcos de los dos nichos que se haçen debajo del altar mayor aunque se pierdan dos lugares de ataudes que son en la parte señalada en la planta: Letras $B$ y $C$, y por no saber que jenero de fabrica es la que alli mas se acostumbra no doy mi pareçer en esto y asi se podria embiar estas plantas para que bistas y reconoçidas el intiento digan las dificultades que se ofreçen y de que jenero de materiales se puede ejecutar.

La otra parte es de los nichos y su ornamento para poner dentro de la capilla mayor los entierros con dos urnas en cada uno que se corresponda a los lados de la epistola y ebanjelio y en la traza que de alla biene para este efeto me a pareçido adbertir que en quanto al sitio en que se quiere poner estos nichos esta bien pues no se pueden poner en medio de la capilla mayor por lo que ocupan las puertas de las sacristias y tribuna si bien fuera mejor que estubieran en el medio pero la correspondençia de los lugares suplira este defeto. Lo otro es que el pedestal en que carga la urna es muy bajo y queda con poca deçencia asi para esto como para poner los escritos que ubieren de tener estos entierros. Lo otro que todo el ornato pareçe pobre sin colunas que el cuerpo ultimo en que se ponen las armas es grande a asi tomando desta traça [perdido] el lugar del sitio de la traça grande algo [perdido] su forma en quanto a poner colunas se a formado una nueba traça con las enmiendas que an pareçido conbenientes para que esta obra quede de mejor adorno y mas fundada arquitectura y el pedestal mas alto y de mayor capaçidad para poner los letreros. No hablo de la materia por no saber las piedras de jaspe y de marmoles que se pueden gastar en aquella villa y asi en esto hiçiera la misma dilijençia que en la obra de la bobeda remitiendo estas traças para que alla se bean y si tienen algo que adbertir y que embien relaçion de las piedras y sus colores con que esta obra se a de executar. En Madrid y abril 19. $1636=$

Joan Gomez / demora [y rúbrica]

\section{AHNOB. BAENA, C.23, D.12}

Mucho me olgado de ver aquí el Maestro que a de acer la bobeda y entierros pues con su ynformaçion se a salido de las dudas que tubo quando se traço la bobeda por no saber la calidad de la tierra en qe se abia de fundar, balor y usso de los materiales que segun lo que se a ajustado entre los dos no se alla ynconbeniente ninguno porque en el que mas se dudaba era el poco conocimiento que se tenia de los fundamentos de la obra de la capilla mayor por ser cossa tan dificultossa ahondar los çimientos y açer bobeda despues de estar hechas las fabricas, ase salido deste cuydado respecto de que es peña biba sobre que cargan los cimientos y aunque en ella se corte lo necessario para el gueco que a de tener la bobeda y sus nichos no puede atormentar la fabrica hecha.

En cuanto a las traças estamos de acuerdo que con ellas siendo Vex a serbido se puede ejecutar la obra y pareçe que el çocalo primero/sobre que an de cargar los pedestales se lebante $m^{a}$ bara mas de lo que esta traçado para que se pueda mejor aRimar la silla y sitial de Vex a el dia que asistiere en la yglesia sin llegar a los entierros.

En quanto a la calidad bondad y balor de los materiales es muy grande la diferençia que açen a los de aqui por tener tan a la mano y tan a proposito como son menester y atendiendo a todo ello pareçe ser obra de hasta quatro mill y quinientos ducados y si se obrara en $M^{d}$ llegara a diez mill por ser mas caros y los oficiales açerse pagar mejor.

Quedo contento que la persona de Luys Gonçalez Baylen la ejecutara bien por lo que entendido de su persona y ser Maestro de satisfaçion que ynporta mucho obras tales se ejecute con buenas manos para que salga cual conbiene al gusto y serbiçio de Vex. ${ }^{a}$.

Tanbien quedamos de acuerdo que si en el discursso desta obra se ofreçiere alguna cossa me lo abisara. En esto y en todo acudire al serbiçio de Vex. ${ }^{a}$ deseando muchas ocasiones para acer demostraçion de lo mucho que deseo serbir a Vex. ${ }^{a}$ a quien gde Dios como deseo. De la parada y agosto 18 de 1639.

Joan Gomez / demora [y rúbrica] 


\section{FUENTES MANUSCRITAS Y DOCUMENTALES}

\section{ACMDB - Archivo Conventual Madre de Dios de Baena}

Libro de los entierros $q$ [ue] ay en el coro y en la yglesia de los señores desta Casa, C.4. ca.1645 [manuscrito; 12 folios; cosido y formando contraportada con el Libro de las profesiones de las monjas de $m^{a}$ de dios de Vaena, comenzado en 1598].

Libro de la Hacienda que este Convento de Madre de Dios tiene y de los papeles de más consideración que en su archivo están..., ca.1620 [manuscrito; 360 folios, con faltas].

\section{AHNOB - Archivo Histórico de la Nobleza}

Fondo Baena, Caja 23, Documentos 7 a 12.

Fondo Baena, Caja 32, Documento 9.

Fondo Baena, Caja 124, Documento 65.

Fondo Baena, Caja 208, Documento 149.

Fondo Baena, Carpeta 322, Documento 28.

Fondo Baena, Carpeta 462, Documentos 20 a 23 y 30.

\section{BIBLIOGRAFÍA}

Blanco Mozo, Juan Luis (2002): Alonso Carbonel (1583-1660), Arquitecto del Rey y del Conde Duque de Olivares, Tesis doctoral, Universidad Autónoma de Madrid. En: http://hdl.handle.net/10486/6258.

Bustamante García, Agustín (1992): "El Panteón del Escorial. Papeletas para su historia”. En: Anuario del Departamento de Historia y Teoría del Arte. Vol. 4, Madrid, pp. 161-215.

Fernández de Béthencourt, Francisco (2003): Historia Genealógica y Heráldica de la Monarquía Española. Sevilla: Fabiola de Publicaciones Hispalenses, 10 tomos.

Fernández de Córdoba, Francisco, Abad de Rute (1954-1964): "Historia de la Casa de Córdoba". En: Boletín de la Real Academia de Córdoba (Trascripción del manuscrito), Córdoba.

Ferrer Valls, Teresa (2008): “Teatro y Mecenazgo en el Siglo de Oro: Lope de Vega y el Duque de Sessa”. En: Egido, Aurora/Laplana, José Enrique (eds.): Mecenazgo y Humanidades en tiempos de Lastanosa. Zaragoza: Instituto de Estudios Altoaragoneses, Institución Fernando el Católico, pp. 113-134.

Galera Andreu, Pedro Antonio (1982): Arquitectura y Arquitectos en Jaén a fines del siglo XVI. Jaén: Instituto de Estudios Giennenses, Diputación Provincial.

González de Amezúa, Agustín (ed.) (1989): Epistolario de Lope de Vega Carpio. Madrid: Real Academia Española, editada originalmente en 1935-1943.

Martín González, Juan José (1959): “E1 Panteón de San Lorenzo de El Escorial”. En: Archivo Español de Arte, núm. 127, Madrid, pp. 199-213.

Moreno Hurtado, Antonio (1986): "La fachada del Instituto 'Aguilar y Eslava'”. En: La Opinión, núm. 2.986, Cabra.

Nieto Cumplido, Manuel (1998): La Catedral de Córdoba. Córdoba: Obra Social y Cultural de Cajasur.

Peláez del Rosal, Manuel (1985): "El cantero Alonso González Bailén”. En: Fuente del Rey, núm. 22, Priego de Córdoba, p. 7.

Rivas Carmona, Jesús (1990): Arquitectura y Policromía. Los mármoles del Barroco andaluz. Córdoba: Diputación Provincial.

Sanz Arauz, David/Abenza Ruiz, Beatriz/Garcés Esteban, Pablo (2007): "Mármoles históricos del sepulcro de los Mendoza en el convento de San Francisco de Guadalajara. Marquetería lapidaria española del siglo XVIII". En: Arenillas, M./Segura, C./Bueno, F./Huerta, S. (eds.): Actas del Quinto Congreso Nacional de Historia de la Construcción. Burgos: Sociedad Española de Historia de la Construcción, pp. 847-854.

Tovar Martín, Virginia (1986): "Juan Gómez de Mora. Arquitecto y Trazador del rey y Maestro Mayor de obras de la villa de Madrid”. En: Juan Gómez de Mora (1586-1648). Madrid: Concejalía de Cultura, pp. 1-162.

Urquízar Herrera, Antonio (2000): "La dotación ornamental de las parroquias del sur del Reino de Córdoba tras la Conquista de Granada". En: Toro Ceballos, Francisco/Rodríguez Molina, José (coords.): III Estudios de Frontera. Convivencia, Defensa y Comunicación en la Frontera. Jaén: Diputación Provincial, pp. 785-792.

Wright, Elizabeth R. (2007): “Los duques de Sessa, sus deudas y disputas. El mecenazgo como patrimonio familiar”. En: García García, Bernardo J./Lobato, María Luisa: Dramaturgia festiva y cultura nobiliaria en el Siglo de Oro. Madrid/Frankfurt am Main: Iberoamericana/Vervuert, pp. 249-267.

Fecha de recepción: 09-VI-2015

Fecha de aceptación: 10-II-2016 